\title{
Optimization of bioethanol production from simultaneous saccharification and fermentation of pineapple peels using Saccharomyces cerevisiae
}

\section{*OIWOH, O; AYODELE BV; AMENAGHAWON, NA; OKIEIMEN, CO}

Department of Chemical Engineering, University of Benin, Benin City, Nigeria

*Corresponding authorE-mail: osamudiamhen.okie-aghughu@uniben.edu

\begin{abstract}
In this study, bioethanol production from the simultaneous saccharification and fermentation (SSF) of pineapple peels using cellulase and Saccharomyces cerevisiae was investigated. A three-factor Box-behnken design (BBD) and response surface methodology (RSM) were employed to study the effect of broth $\mathrm{pH}(2-6)$, yeast loading (2$10 \mathrm{~g} / \mathrm{l})$ and ammonium sulphate concentration (1-5 g/l) on the bioethanol production process. Optimum values of $\mathrm{pH}$, yeast loading and ammonium sulphate concentration of $6.0,8 \mathrm{ml}$ and $5 \mathrm{~g} / \mathrm{l}$, respectively were obtained for maximum bioethanol concentration of $5.82 \% \mathrm{v} / \mathrm{v}$. The results obtained show the possibility of using pineapple peels as feedstock for bioethanol production via SSF method. Moreover, the use of BBD and RSM as robust technique for determining the effect of parameters and optimum conditions for bioethanol production has been ascertained.
\end{abstract}

\section{DOI: https://dx.doi.org/10.4314/jasem.v21i7.5}

COPYRIGHT: Copyright $\odot 2017$ Oiwoh et al. This is an open access article distributed under the Creative Commons Attribution License (CCL), which permits unrestricted use, distribution, and reproduction in any medium, provided the original work is properly cited

DATES: Received 3 August 2017; received in revised form 8 September 2017; accepted 30 November 2017

Keywords: Bioethanol; Box-behnken design; Fermentation; Optimization; Pineapple peels

The excessive consumption of non-renewable energy has greatly resulted in environmental deterioration and public health problems (Kahia et al., 2016). This in turn has resulted in the need to find a source of renewable energy. Bioethanol produced by fermentation of plant biomass is considered to be an environmentally friendly alternative to fossil fuels and has the potential to suitably replace gasoline as a transportation fuel (Itelima et al., 2012). The economics of bioethanol production is significantly influenced by the cost of the raw materials and in order to reduce this cost, cheap materials are sourced as feedstock for ethanol production (Franko et al., 2016). As a result, the search for renewable biomass sources has focused primarily on plant biomasses that are usually regarded as waste and possess lignocellulosic materials (Fish, Bruton and Russo, 2009). The use of lignocellulosic residues in the production of bioethanol would ensure continuous energy supply because they are less expensive than starchy and sucrose producing crops (commonly used in bioethanol production) and are available in large quantities.

An example of an important lignocellulosic residue that can be used in bioethanol production is pineapple peels. Pineapple is the third most important tropical fruit in the world after Banana and Citrus and Nigeria, ranks 7th on the list of world producers of pineapple as well as is the leading producer of pineapple in Africa. (Adegbite et al.2014). However, there are a lot of unused excess parts of the pineapple, notably the peels, which are considered as waste and contribute to the country's garbage problem. These peels are a major component of domestic and industrial waste worldwide, rich in sugar and lignocellulosic components and account for $29-40 \%(w / w)$ of the total pineapple weight. Their high sugar and lignocellulosic components could make them a potentially viable feedstock for bioethanol production.

Bio-ethanol fermentation process is usually done by species of the yeast Saccharomyces because it ferments glucose to ethanol and is known for its high insensitivity to temperature and substrate concentration, rapid fermentation rates as well as high ethanol tolerance. (Avril Rodiel Bries, 2008). In bioethanol fermentation from lignocellulosic materials, pretreatment and hydrolysis are usually needed to convert these materials to monomeric sugars before fermentation can take place. Enzymes are usually employed for the hydrolysis of these materials and this is considered a very viable strategy since it offers advantages over other chemical conversion routes of higher yields, minimal byproduct formation, low energy requirements, mild operating conditions, and environmentally friendly processing (Zheng, Pan and Zhang, 2009). In using the enzymatic route, studies have shown that it is advantageous to use the simultaneous saccharification and fermentation (SSF) route in the 
production of bioethanol. (Avril Rodiel Bries, 2008). In this process, glucose released by the enzyme, cellulase is simultaneously converted to ethanol by the fermenting microorganism. One of the advantages of this process is that ethanol fermentation is carried out in a single bioreactor which provides a reduction in the overall fermentation time and a reduction in the investment and operational costs (Białas et al., 2010).

Optimization of significant process conditions is a very important stage in order to develop an efficient and cost-effective bioprocess. (Gade, 2009). Usually in optimization processes, the traditional one-factorat-a-time method is employed but this method is often cumbersome and time consuming. (Nadya et al, 2012). As a result, response surface methodology (RSM) which is a useful tool that helps to identify the effects of several process variables influencing a particular response by varying them simultaneously and carrying out a limited number of experimental runs is now more commonly employed. (Cazetta et al., 2007)

The objective of this study was to optimize important parameters for the bioethanol production from pineapple peels via simultaneous hydrolysis and fermentation using Saccharomyces cerevisiae.

\section{MATERIALS AND METHODS}

Sample Collection and Preparation: Pineapple peels obtained from a fruit vendor were washed, cut in small pieces and then blended until a pulpy mass was obtained. It was then stored in the refrigerator prior to use.

Simultaneous Saccharification and Fermentation (SSF)

The batch SSF was performed at a solid loading of $15 \%(\mathrm{w} / \mathrm{v})$ at room temperature for 72 hours with a final working volume of $100 \mathrm{ml}$. The unsterilized pulp was supplemented with mineral media without glucose and the $\mathrm{pH}$ was adjusted by adding $0.5 \mathrm{M}$ Sodium Hydroxide. After the enzymes were added the mixture was left for 1 hour for pre-saccharification at room temperature. Thereafter the inoculum was added at a concentration of $5 \mathrm{~g} / \mathrm{l}$ of wet cells. The parameters considered were: yeast loading (\%v/v), $\mathrm{pH}$, and concentration of ammonium sulphate $(\mathrm{g} / \mathrm{L})$.

\section{Determination of Bioethanol produced from Pineapple broth}

At the end of the fermentation, liquid samples were taken from the fermentation broth. The samples were filtered and the filtrate was used to determine ethanol concentration. Ethanol concentration was determined using High Performance Liquid Chromatography (HPLC) equipped with an Ultra violet (UV) detector and a C18 column. The column was used to separate ethanol from samples using pure Acetonitrile as mobile phase at a flow rate of $1 \mathrm{ml} / \mathrm{min}$ and injection volume of $10 \mu 1$.

Process Optimization by Response Surface Methodology: A three-factor Box-Behnken Design (BBD) was employed for the experimental design. The responses obtained from the BBD were optimized using response surface methodology. Each of the factors to be optimized was coded at three levels which gave range for yeast loading (2-10\% $\mathrm{v} / \mathrm{v}), \mathrm{pH}(2-6)$, concentration of ammonium sulphate $\left(\left(\mathrm{NH}_{4}\right)_{2} \mathrm{SO}_{4}\right)$ (1-5 g/L). The bioethanol concentration was chosen as the response for process optimization using RSM. The experimental design carried out using Statistica version 22 (Dell inc. USA) was made up of 17 runs. Experimental observations from the fermentation process were analyzed and fitted according to Equation (1) as a second-order polynomial equation including main effects and interaction effects of each variable. Analysis of variance (ANOVA) and response surface plots were generated using Design Expert software. The optimized value of the independent variables for optimum response was determined using numerical optimization.

$Y_{i}=b_{o}+\sum b_{i} X_{j}+\sum b_{i j} X_{i} X_{j}+\sum b_{i i} X_{i}^{2}+e_{i}$

where $Y_{i}$ is the dependent variable or predicted response, $X_{i}$ and $X_{j}$ are the independent variables, $b_{o}$ is offset term, $b_{i}$ and $b_{i j}$ are the single and interaction effect coefficients and $e_{i}$ is the error term.

\section{RESULTS AND DISCUSSION}

Optimization of bioethanol production using RSM: The optimization of bioethanol production from SSF of pineapple peals was performed using BBD. The responses of the experimental runs obtained from the BBD are depicted in Table 1. The BBD is a distinctive experimental design due to occurrence of treatment combinations at the midpoints of the experimental space edge. As a result of this, it is easier to estimate the first and second order coefficients using BBD. Besides, due to fewer numbers of runs in $\mathrm{BBD}$ compare to $\mathrm{CCD}$, the cost of running the experiment is less.

The use of BBD in this study resulted in a non-linear second order model between the input variables $(\mathrm{pH}$, yeast loading and $\left(\mathrm{NH}_{4}\right)_{2} \mathrm{SO}_{4}$ concentration) and the output variable (bioethanol concentration). The significance and adequacy of the RSM model shown in Equation (1) was evaluated using ANOVA (Table 2) and coefficient of determination $\left(R^{2}\right)$. Optimum 
conditions obtained using the regression model were $\mathrm{pH}$ 6, yeast loading $8 \mathrm{ml}$ and concentration of ammonium sulphate, $5 \mathrm{~g} / \mathrm{l}$ which gave an optimum ethanol concentration value of $5.82 \%(\mathrm{v} / \mathrm{v})$.

Table 1: Experimental and predicted results of the ethanol production process

\begin{tabular}{ccccc}
\hline $\begin{array}{c}\text { Experimental } \\
\text { runs }\end{array}$ & pH $(\mathrm{A})$ & $\begin{array}{c}\text { Yeast loading } \\
(\mathrm{g} / \mathrm{l})(\mathrm{B})\end{array}$ & $\begin{array}{c}\text { Concentration of } \\
\left(\mathrm{NH}_{4}\right)_{2} \mathrm{SO}_{4}(\mathrm{~g} / \mathrm{l})(\mathrm{C})\end{array}$ & $\begin{array}{c}\text { Bioethanol } \\
\text { concentration }(\% \mathrm{v} / \mathrm{v})\end{array}$ \\
\hline 1 & 2 & 2 & 3 & $(\mathrm{Y})$ \\
2 & 4 & 10 & 5 & 2.67 \\
3 & 6 & 10 & 3 & 2.61 \\
4 & 4 & 6 & 3 & 1.76 \\
5 & 6 & 2 & 3 & 1.70 \\
6 & 4 & 6 & 3 & 1.38 \\
7 & 4 & 2 & 5 & 0.48 \\
8 & 4 & 10 & 1 & 2.03 \\
9 & 4 & 2 & 1 & 2.08 \\
10 & 6 & 6 & 5 & 5.49 \\
11 & 2 & 10 & 3 & 3.87 \\
12 & 2 & 6 & 5 & 4.32 \\
13 & 4 & 6 & 3 & 1.38 \\
14 & 4 & 6 & 3 & 3.92 \\
15 & 6 & 6 & 1 & 1.29 \\
16 & 4 & 6 & 3 & 7.30 \\
17 & 2 & 6 & 1 & \\
\hline
\end{tabular}

Table 2: Analysis of variance (ANOVA) for the optimization of bioethanol concentration using Box-Behnken Design

\begin{tabular}{llllll}
\hline Source & $\begin{array}{l}\text { Sum of } \\
\text { Squares }\end{array}$ & Df & $\begin{array}{l}\text { Mean } \\
\text { Square }\end{array}$ & $\begin{array}{l}\text { F } \\
\text { Value }\end{array}$ & $\begin{array}{l}\text { p-value } \\
\text { Prob }>\text { F }\end{array}$ \\
\hline Model & 48.24545 & 9 & 5.360605 & 132.8884 & $<0.0001$ \\
A-pH & 2.572769 & 1 & 2.572769 & 63.77848 & $<0.0001$ \\
B-yeast loading & 2.353969 & 1 & 2.353969 & 58.35447 & 0.0001 \\
C-conc of ammonium sulphate & 0.59308 & 1 & 0.59308 & 14.70235 & 0.0064 \\
AB & 0.004225 & 1 & 0.004225 & 0.104737 & 0.7557 \\
AC & 5.791328 & 1 & 5.791328 & 143.566 & $<0.0001$ \\
BC & 1.190244 & 1 & 1.190244 & 29.50595 & 0.0010 \\
$A^{2}$ & 23.05349 & 1 & 23.05349 & 571.492 & $<0.0001$ \\
B $^{2}$ & 4.714474 & 1 & 4.714474 & 116.871 & $<0.0001$ \\
C $^{2}$ & 8.09001 & 1 & 8.09001 & 200.5499 & $<0.0001$ \\
Residual & 0.282374 & 7 & 0.040339 & & \\
Lack of Fit & 0.025075 & 3 & 0.008358 & 0.12994 & 0.9374 \\
Pure Error & 0.257299 & 4 & 0.064325 & & \\
Cor Total & 48.52782 & 16 & & & \\
R- squared & 0.9942 & & & & \\
Adjusted R-squared & 0.9867 & & & & \\
Predicted R-squared & 0.9834 & & & & \\
Adequate Precision & 44.14976 & & & & \\
\hline
\end{tabular}

The ANOVA results for the BBD of the bioethanol production from SSF is depicted in Table 2. The quadratic model obtained in coded form for the optimization of the bioethanol production is shown in Equation (1).

$\mathrm{Y}=1.47-0.57 \mathrm{~A}+0.54 \mathrm{~B}-0.27 \mathrm{C}-0.032 \mathrm{AB}+$ $1.20 \mathrm{AC}+0.55 \mathrm{BC}+2.34 \mathrm{~A}^{2}-1.06 \mathrm{~B}^{2}+1.39 \mathrm{C}^{2}(1)$

Based on the ANOVA results in Table 2, it can be seen that the p-value which determine the statistical significance of the model obtained from the RSM is greater $<0.0001$, an indication that the model has over $95 \%$ confidence level in terms of predictability. In addition, the robustness of the model can also be ascertained from the values of the $\mathrm{R}^{2}(0.9942)$.
This implies that the experimental data was well fitted into the RSM model. The predicted $\mathrm{R}^{2}(0.9834)$ value is a measure of how good a prediction of the model gives to the response value while the adjusted $\mathrm{R}^{2}(0.9867)$ value represents the amount of variation in the design model. Both the predicted $\mathrm{R}^{2}$ and the adjusted $\mathrm{R}^{2}$ values should be within approximately 0.2 of each other to be in reasonable agreement. The significance of the statistical model shown in Table 2 was also evaluated by the F-test.

The F-value of 132.89 indicate that the f-distribution under the null hypothesis is statistically significant. Further proof of the model adequacy in explaining the data is the R-squared value. This shows that the regression model equation gives an accurate 
description of the experimental data. Another factor which measures the adequacy of the model is the value of adequate precision obtained.

A ratio greater than 4 is usually desirable. In this study, a ratio of 44.150 was obtained which indicates an adequate signal and as a result, this model can be used to navigate the design space.

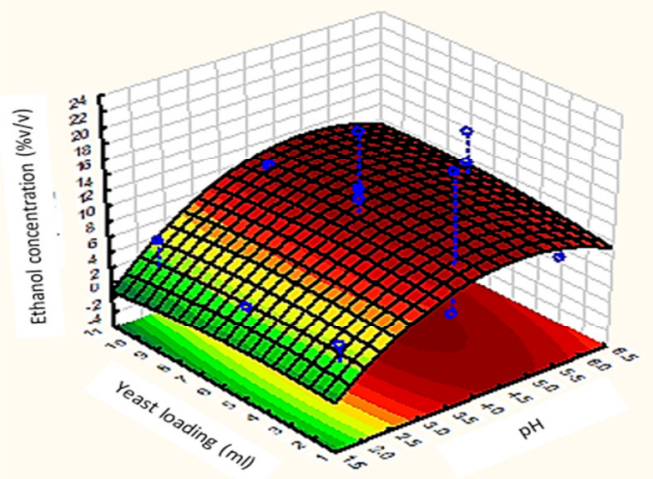

Fig 1: 3D response plots showing the effect of $\mathrm{pH}$ and yeast loading on ethanol production

Figure 1 shows the effect of $\mathrm{pH}$ and yeast loading on the bioethanol concentration. It can be seen that both yeast loading and $\mathrm{pH}$ significantly influence the bioethanol concentration. This is evident from the ANOVA analysis that gave p-values $<0.0001$ for both yeast loading and $\mathrm{pH}$. However, a close observation shows that $\mathrm{pH}$ has more significant effect on the bioethanol concentration compare to yeast loading. The analysis of the response plots show that an optimum $\mathrm{pH}$ value of 6 was obtained for maximum ethanol production. $\mathrm{pH}$ is one of the important factors that affect the performance of Simultaneous Saccharification and Fermentation and various studies have shown that the optimum $\mathrm{pH}$ value for ethanol production is between 5 and 6 (Afifi et al, 2011) which is in line with what was obtained in this study. It can also be observed that ethanol concentration increases with increase in yeast loading up to maximum of $8 \mathrm{ml}$ and drops thereafter. This may be due to the fact that beyond this value, yeast cells present are increased and so competition for available substrate sets in which brings about reduction in efficiency of yeast cells.

Figure 2 depicts the effect of $\mathrm{pH}$ and ammonium sulphate on the bioethanol concentration. Interestingly, both $\mathrm{pH}$ and the ammonium sulphate influence the bioethanol concentration as clearly seen in the p-value which is less than 0.0001. Besides, an increase in the concentration of ammonium sulphate favoured the increased production of ethanol. This is as a result of the fact that addition of ammonium sulfate in sufficient quantities supports high production of bioethanol. With the introduction of sufficient nutrients to the fermentation process, the yeast can multiply quickly and consume glucose to produce ethanol more effectively.

It can also be observed that in the presence of relatively high concentrations of ammonium sulphate, the rate of fermentation increased up to a $\mathrm{pH}$ optimum of 6 which is line with studies by Nadya et al. (2012) who reported that an optimum $\mathrm{pH}$ value of 6 was obtained for the production of ethanol from pineapple peel extract.

It can also be observed that in the presence of relatively high concentrations of ammonium sulphate, the rate of fermentation increased up to a $\mathrm{pH}$ optimum of 6 which is line with studies by Nadya et al. (2012) who reported that an optimum $\mathrm{pH}$ value of 6 was obtained for the production of ethanol from pineapple peel extract.

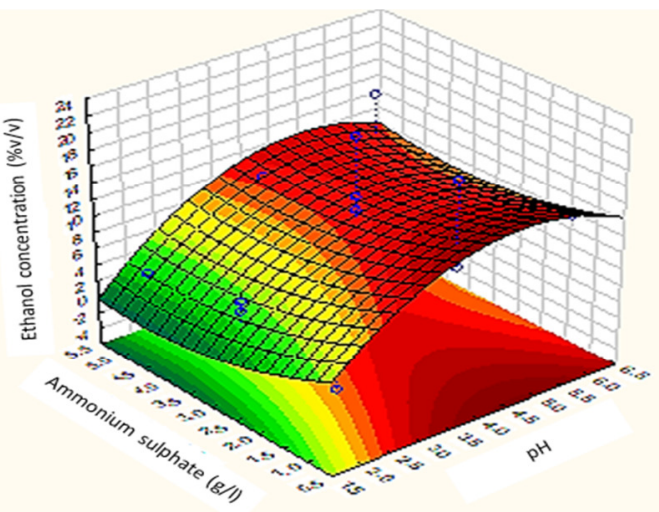

Fig 2: 3D response plot showing the effect of $\mathrm{pH}$ and ammonium sulphate on ethanol production

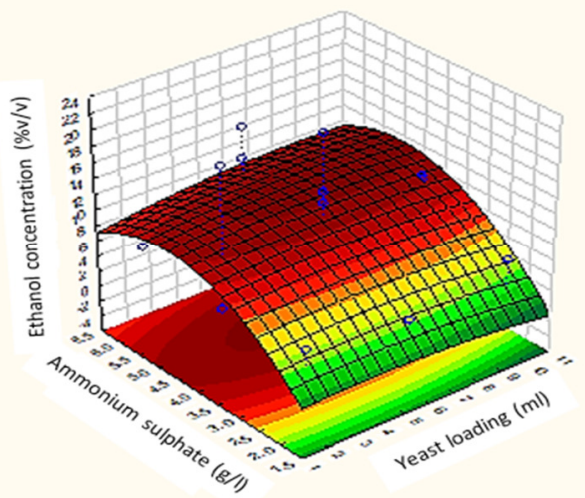

Fig 3: 3D response plot showing the effect of yeast loading and ammonium sulphate on ethanol production

Figure 3 above shows the effect of yeast loading and ammonium sulphate on ethanol production. It is seen that there is the interaction between the amounts of ammonium sulphate introduced into the SSF broth 
and the yeast loading has significant influence on the bioethanol concentration. However, the amounts of ammonium sulphate have more effect on the bioethanol concentration compare to yeast loading. The reason for this can be explained by various studies that have been carried out. Irhan et al. (2010) reported that an increase in innoculum size brings about an increase in biomass concentration and a corresponding increase in bioethanol concentration although an optimum size is required beyond which the ethanol concentration reduces as a result of the fact that competition for food by yeast cells increases. Also, studies by Mendes-Ferreira et al, (2004) have shown that supplementation with ammonium sulphate during fermentation increases fermentation rate. In line with these studies, it is seen from Figure 3 that the bioethanol concentration increased as the concentration of ammonium sulphate increased up to an optimum value of $5 \mathrm{~g} / \mathrm{l}$ and yeast loading increased up to an optimum value of $8 \mathrm{ml}$ beyond which it is noticed that ethanol concentration begins to reduce which can be accounted for by the fact that at this point competition by yeast cells start to occur.

Comparison between the Observed bioethanol concentration and the predicted values: The parity plots showing the comparison between the observed bioethanol concentration and the RSM predicted values are depicted in Figure 4. It can be seen that the observed values of the bioethanol concentration from the experimental runs is in good correlation with the RSM predicted values. This shows the robustness of the RSM as a good predictive tool besides being used for optimization. Moreover, it also indicate that the regression model equation gives an accurate representation of the experimental data.

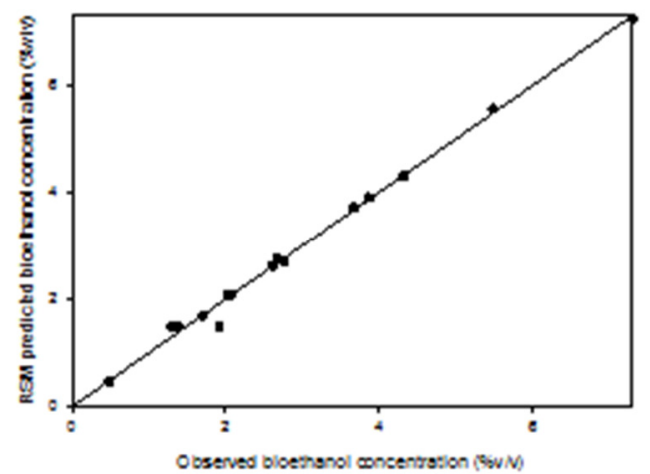

Fig 4: Parity plot of the observed and predicted values of the bioethanol concentration

Conclusion: Response Surface Methodology has been employed for the optimization of bioethanol production from simultaneous saccharification and fermentation of pineapple peels using Saccharomyces cerevisiae. The interaction effects from the RSM shows that $\mathrm{pH}$, yeast loading and ammonium sulphate significantly influences the bioethanol concentration.

\section{REFERENCES}

Adegbite. O; Oni. O; Adeoye. I. (2014). Competitiveness of Pineapple Production in Osun State, Nigeria. J. Econ. Sustain. Develop. 5 (2): 205-214

Magdy, MA; Abd El-Ghany, TM; Mohamed, AA; Taher, MT; Khaled, EG. (2011). Biorefinery of Industrial Potato Wastes to ethanol by Solid State Fermentation, Res. J. Agric. Biol. Sci. 7(1):126-134

Białas, W; Daria, S; Włodzimierz, G. (2010). Fuel ethanol production from granular corn starch using Saccharomyces cerevisiae in a long term repeated SSF process with full stillage recycling Biores. Technol. 101: 3126-3131

Cazetta, ML; Celligoi, MAPC; Buzato, JB; Scarmino, IS. (2007). Fermentation of molasses by Zymomonas mobilis: Effects of temperature and sugar concentration on ethanol production. Biores. Technol. 98: 824-2828

Frankó, B; Galbe, M; Wallberg, O. (2016). Bioethanol production from forestry residues: A comparative techno-economic analysis. Appl. Energy. 184: 727-736.

Gade, PR (2009). Multi-Objective Optimization: Techniques and Applications in Chemical Engineering. In Advances in Process Systems Engineering. World Scientific Publishing Co. Pte. Singapore.

Hasunuma, T; Kondo, A. (2012). Consolidated bioprocessing and simultaneous saccharification and fermentation of lignocellulose to ethanol with thermotolerant yeast strains. Process Biochem. 47:1287-1294

Irfan, T; Katherine, L; Bialka, AD; Mustafa, K. (2010). Ethanol production from carob extract by using Saccharomyces cerevisiae. Biores. Technol. 101: 5290-5296

Itelima, J; Onwuliri, F; Onwuliri, E; Onyimba, I; Oforji, S. (2013). Bio-Ethanol Production from Banana, Plantain and Pineapple Peels by Simultaneous Saccharification and Fermentation Process. Inter. J. Environ. Sci. Develop. 4 (2); 213-216 
Kahia, M; Aïssa, MSB; Charfeddine, L. (2016). Impact of renewable and non-renewable energy consumption on economic growth: New evidence from the MENA Net Oil Exporting Countries (NOECs). Energy, 116: 102-115.

Swain, MR; Mishra, J; Thatoi, H. (2013). Bioethanol production from sweet potato (Ipomoea batatas L.) flour using co-culture of Trichoderma sp. and Saccharomyces cerevisiae in solid-state fermentation. Brazilian Archives Biol. Technol. 56(2): 171-179.
Mendes-Ferreira, A; Mendes-Faia, A; Leão, C. (2004). Growth and fermentation patterns of Saccharomyces cerevisiae under different ammonium concentrations and its implications in winemaking industry. J. Appl. Microbiol. 97(3); 540-545.

Hajar, N; Zainal, S; Atikah, O; Elida, TT. (2012). Optimization of ethanol fermentation from pineapple peel extract using response surface methodology (RSM). Proceed. World Acad. Sci. Engineer. Technol. 72: 641.

Raji, YO; Jibril, M; Misau, IM; Danjuma, BY. (2012). Production of vinegar from pineapple peel. Inter. J. Adv. Sci. Res. Technol. 3(2): 656666. 